\title{
Virtual Reality Therapy in Long Term Care Resident Older Adults With Dementia: A Case Series
}

\author{
Munira Sultana ( $\triangle$ msulta@uwo.ca ) \\ Western University https://orcid.org/0000-0002-3696-4122 \\ Dr. Karen Campbell \\ Western University \\ Morgan Jennings \\ Western University \\ Manuel Montero-Odasso \\ Western University \\ Joseph. B. Orange \\ Western University \\ Jill Knowlton \\ primacare Living Solutions Inc. TM \\ Armin St. George \\ Crosswater Digital Media LLC \\ Dianne Bryant \\ Western University
}

\section{Research article}

Keywords: Behavioural and Psychological Symptoms of Dementia, virtual reality, Long-Term Care home

Posted Date: March 5th, 2020

DOI: https://doi.org/10.21203/rs.3.rs-16210/v1

License: (c) (1) This work is licensed under a Creative Commons Attribution 4.0 International License.

Read Full License 


\section{Abstract}

BACKGROUND: Behavioural and psychological symptoms of dementia (BPSD) worsens as dementia progresses, intensifies caregiver distress and consequent institutionalization. We wanted to evaluate 1) feasibility of Virtual Reality (VR) as cognitive stimulation therapy for BPSD in a Long-Term Care (LTC) home, 2) participants' tolerance for the therapy, 3) facilitators and barriers to implementing VR therapy, 4) sensitivity to change of the participants' BPSD to VR therapy, and 5) longitudinal construct validity of BPSD measuring tools.

METHODS: A single site (Henley Place at London, Ontario) case series with a convenience sample (24 older adult residents with moderate to severe dementia). Intervention was 30 minutes of VR therapy with Broomx@ , five days a week for two weeks. The change in BPSD was measured with Cornell Scale for Depression in Dementia (CSDD), Cohen-Mansfield Agitation Inventory (CMAI) scale, Dementia Observation System (DOS) scale, and proportion of night-time sleep. We validated selected tools with Global Rating of Change (GRC) scale.

RESULTS: Implementing VR therapy was possible at Henley Place (recruitment rate $=40 \%$, the adherence rate $=21 \%$, and the attrition $=0 \%$ ) and participants could tolerate it. No emergency transfers or one-to-one staff use were recorded during the intervention period.

CONCLUSION: VR therapy can be implemented in a LTC home. TRIAL REGISTRATION: The study was not registered as clinical trial. We obtained ethics approval from ADVARRA Canada Ethics Board before recruiting participants for the study.

\section{Background}

Dementia is a progressive neurocognitive condition, predominantly affecting older adults that evolves to disability and, eventually, mortality [1]. There is no cure for dementia [1]. According to the Public Health Agency of Canada [2], the number of Canadians with dementia was about 402,000 in 2014. The annual dementia incidence rate in Canada was 360 per 100,000 people in 2011 [3]. In 2016, dementia ranked the fifth leading cause of death worldwide [4]. Dementia accounted for $6.3 \%$ ( $95 \%$ confidence interval [CI] $5.4 \%$ to $7.5 \%$ ) of disability-adjusted life in years for the people aged 70 years and over [5].

Behavioural and psychological symptoms of dementia (BPSD) include apathy, depression, sleep disorders, agitation, aggression, and psychosis [6]. The most frequent disturbances reported were anxiety/agitation/aggression $(52 \% ; 95 \% \mathrm{Cl} 47-57 \%)$, apathy $(36 \%$; $95 \% \mathrm{Cl} 31-41 \%)$, depression $(32 \%$; $95 \%$ $\mathrm{Cl} 28-37 \%)$, sleep disturbance $(27 \% ; 95 \% \mathrm{Cl} 23-32 \%)$ and irritability $(27 \% ; 95 \% \mathrm{Cl} 23-32 \%)$ [7]. Lyketsos and colleagues [7] reported $75 \%(95 \% \mathrm{Cl} 70-79 \%)$ of dementia participants exhibited at least one BPSD from the onset of their cognitive symptoms. Family members of individuals with dementia reported that their loved ones' BPSD are the reason for their decision in placing them in a Long-Term Care (LTC) home $[8,9]$. 
Managing BPSD is often challenging as the causal relationship of the symptoms and pathophysiology is complex [10]. For example, an individual with dementia may exhibit BPSD due to pain necessitating pain management instead of psychotherapy [11]. However, available pharmacotherapies for BPSD has limited effectiveness in terms of possible serious side-effects resulting from multi-morbidity or polypharmacy or age-related altered metabolism [12]. Consequently, BPSD management is increasingly focusing on maintaining an optimal quality of life with non- pharmacotherapies [13].

The Virtual Reality (VR) therapy is a type of non-pharmacotherapy focusing on sensory stimulation that offers a computer-generated virtual environment imitating real world and can create an experience of a physical reality [14]. An individual using VR therapy can look around or move around in an artificial world [14]. This technology requires the user to either use a headset or a projector (e.g. BroomX@) to generate realistic images, sounds and other sensations that simulate an user's physical presence in a virtual or imaginary environment [14]. BroomX® provides the immersive experience through a projection device having automatic control to conform the visuals to a $360^{\circ}$ experience no matter the size of the room, or what furniture is in the room [15].

To date there is no published research about the use of VR therapy affecting BPSD in LTC residents with moderate to severe dementia. Therefore, we decided to explore the feasibility of VR therapy in a LTC home.

Our objectives were to determine, 1) the rate of recruitment, adherence and attrition; 2) participants' tolerance for the VR therapy; 3 ) facilitators and barriers to implementation of VR therapy; 4) the sensitivity to change of selected outcome measures; and 5) the longitudinal construct validity of selected outcome measures within a sample of adults with moderate to severe dementia undergoing VR therapy.

\section{Methods}

\section{Study design}

A single site case series.

\section{Participants}

Older adults (aged $\geq 65$ years) residing in Henley Place LTC at London ON Canada with a Cognitive Performance Scale (CPS) score between 3 to 5 were eligible to participate in this study. Ontario LTC homes regularly evaluate their residents' cognition with CPS score [16]. The CPS includes four areas: memory, decision-making skills, communication and eating [17]. Residents experiencing no difficulties in these four areas score 0 , whereas residents having severe memory problems and are unable to make daily decisions or feed themselves or are comatose score 6 on the CPS scale [17]. A CPS score 0 indicates no dementia, whereas a score of 1-2 indicates mild, score of 3 indicates moderate, and score of 4-6 indicates severe dementia [17]. 
We excluded those diagnosed with epilepsy, those who were blind, at end of life, and unable to communicate in English. We also excluded those having Substitute Decision-Maker (SDM) appointed as Public Guardian and Trustee.

One Henley Place staff member identified the possible participants using their CPS score. Once identified, the Henley Place staff spoke with participants' SDM face-to-face or by phone to learn if the SDM would agree to be contacted for a possible study participation. Once agreed, the Principal Investigator (PI) and Research Assistant (RA) contacted the SDM from November 26, 2018 to January 04, 2019 to recruit participants.

\section{Intervention}

The intervention was VR therapy using BroomX@. We provided VR experience using a headset at the beginning of the 2-week intervention period to five participants. The PI and RA noticed that the participants felt uncomfortable using the headset as it limited their vision, was too loud, and was heavy. Moreover, the pilot study was conducted in December and January, which is flu season in Ontario LTC. Therefore, we disinfected the headset after each use with a disinfecting liquid, challenging the time management of the intervention. Therefore, we provided VR therapy using a BroomX@ projector instead of a headset to accommodate participants' discomfort and practicality of time management.

The Broomx@ consists of a MK Player 360@ hardware and a software [18]. A MK Player $360 \odot$ is a projection device with light and sound control that can display $360^{\circ}$ videos on a frameless screen (a room) [18]. The Broomx@ $@$ software provides interactive contents accessed by a smartphone app (See Fig. 1: Technical information on Broomx@) [18]. This technology is currently being used in hotels, restaurants, night clubs, retail and exhibitions, and healthcare [18].

A MK Player 360@ projector was used either in a predetermined intervention area or in the participants' own room depending on their mobility status. We covered resident's TV, brought down his/her wall hangings, closed his/her windows and door curtains for a clearer visualization of VR images when setting up MK Player 360@ projector in a resident's room. We noticed that participants got agitated when we were setting up the hardware and software in their own rooms probably because our activities confused them. We also realized that assembling and disassembling VR hardware at participant's own room was time consuming during the first week of the intervention period. From that time forward, the RA assembled the BroomX@ in the intervention area before the participant entered the room. The maximum duration and frequency of the intervention was 30 minutes, five days a week (Monday to Friday) for two weeks. The timing of the intervention was customized for each participant to avoid their usual lunch time, visiting hours, and nap time. However, the two-week intervention schedule was fixed for the convenience of the project. If a participant missed the intervention for the day for any reason, there was no makeup session on a different day. Crosswater Digital Media (https://crosswater.net/) developed a library with pleasing images of nature, set to music (72 beats/minute) for this study. The RA selected the library items for each participant personalized to his/her experiences and preference according to information supplied by family members. If a participant preferred a particular library item, the RA selected that item several times. 
There was no limit to the frequency or variety of the played library items. The intervention was stopped if the participants became agitated with a specific VR library item.

The staff (PSW) caring for the resident were on call during the intervention in case the resident needed assistance. The risk for falls, was reduced by having the RA sit with the participant all time.

\section{Outcome Measures and Statistical Methods}

To address the objective 1, we measured the a) the proportion of consenting participants to eligible participants over the 6-week recruitment period, b) the proportion of participants attending 10 intervention sessions to the number of participants allocated to the intervention, and c) the proportion of participants with incomplete outcome data to the number of participants allocated to intervention.

To address objective 2, we measured a) the proportion of participants who were able to tolerate at least $80 \%$ of the planned sessions $\mathrm{b}$ ) the mean length of participants' VR experience in minutes per session, $\mathrm{c}$ ) number of times each type of negative behaviour observed and the proportion of participants who experienced each negative behaviour, d) number of times each type of positive behaviour was observed and the proportion of participants who experienced each positive behaviour, e) number of Adverse Events $(A E)$ during the intervention period, $f$ ) health care resources used (i.e. the number of participants requiring transfers to emergency, number of participants requiring one-to-one staff use, psychotropic drug prescription, and change in Euro-Qol 5-Dimention [EQ-5D]) to indirectly indicate their tolerance to VR therapy.

According to the Need Driven Behaviour Model [19], an individual with dementia expresses his/her physical/emotional needs or exhibits his/her dementia symptoms through physical/verbal expressions/gestures. As per this model, we reported the following behaviours as "negative": agitation, wandering, hitting (including self), kicking, grabbing onto people, pushing, throwing objects, biting, scratching, spitting, hurting self or others, tearing objects or destroying property, making physical/verbal sexual advances, inappropriate dressing or disrobing, intentional falling, eating/drinking inappropriate substance, handling objects inappropriately, hiding objects, hoarding objects, performing repetitive mannerisms, screaming, cursing or verbal aggression, repetitive sentences or questions, strange noises (weird laughter or crying), complaining, constant unwarranted request for attention or help, pulling away/walking away, perseveration of word/repetitive talking, raising tone of voice, resisting, and not eating. We labeled the following behaviours as "positive": being seated still, being focused, sleeping, being calm, smiling, and communicating verbally/non-verbally, based on staff members' experience with the residents at Henley Place LTC.

We defined AE as any event due to being in a VR therapy session leading to emergency transfer, hospitalization, death, a persistent or significant incapacity or substantial disruption of the participants' ability to conduct the activities of daily living regardless of a causal relationship with VR therapy.

Transfers to emergency and one-to-one staff usage indicated acute decline or worsening of a resident's health. For instance, Henley Place may provide a resident one-to-one staffing if he/she causes another 
resident a physical incident or a sexual incident; becomes physically aggressive (non-manageable) with drug and other therapy; has history of a similar behaviour that ended up on having one-to-one staff usage in the recent past; is in risk of potential self-harm; exhibits an agitated aggressive behaviour or a wandering behaviour; and is at risk of being victimized by other residents.

Psychotropic drugs refer to any drug affecting mental processes and behaviour [20]. Psychotropic drugs include, but are not limited to, antipsychotics, antidepressants, antianxiety drugs, mood stabilizers, anticonvulsants, and hypnotics [20].

The EQ-5D scale is a generic (disease non-specific) quality of life tool, insightful in identifying which dimensions of health are most affected by a given condition or treatment [21]. The tool has five domains: mobility, self-care, usual activities (e.g. work, study, housework, family or leisure activities), pain/discomfort, and anxiety/depression with five possible answers for each domain $(1=$ no problem, $2=$ slight problem, $3=$ moderate problem, $4=$ severe problem, $5=$ unable to do/extreme problem) [21]. EQ-5D is feasible for individuals with dementia [22].

Either PI or RA recorded and labelled participants' behaviours during the VR sessions based on her direct observation, completed VR therapy records and AE forms, and archived the number of emergency transfers, one-to-one staff usage, and psychotropic drug prescription from the participant's medical chart. The Henley Place staff members completed the EQ-5D scale.

To address objective 3 , we reported a) the number of times a library item was selected, b) whether the SDM was present during the VR sessions, and c) factors that were observed to be enabling or d) disabling during the VR experience from the VR therapy records completed by either PI or RA.

To address objective 4, we collected the pre-to post (before any VR therapy took place [baseline] and at the end of second week of therapy) change of BPSD with Cornell Scale for Depression in Dementia (CSDD), Cohen-Mansfield Agitation Inventory (CMAI) scale, proportion of night-time sleep, and Dementia Observation System (DOS) scale. We reported the scales' sensitivity to change with Effect Size (ES).

BPSD are usually measured with subjective psychometric tools, originally developed to rate feelings or opinions or attitudes [23]. A systematic review located 83 BPSD tools focusing either on depression $(n=$ $46)$ or irritability $(n=37)$ or non-aggressive agitation $(n=26)$ or anxiety $(n=22)$ or hallucination $(n=21)$ or delusion $(n=20)$ or wandering $(n=22)$ or apathy $(n=17)$ or sleep problems $(n=14)$ [23]. According to Linde and colleagues [23], the frequently used BPSD tools for older adults in clinical settings are the Cambridge Mental Disorders of the Elderly Examination (CAMDEX) [24], the Geriatric Mental State Schedule (GMS)/Automated Geriatric Examination for Computer Assisted Taxonomy (AGECAT) [25], the Apathy Evaluation Scale (AES) [26], the Geriatric Depression Screening scale (GDS) [27], the Neuro Psychiatric Inventory (NPI) [28], the Cornell Scale for Depression in Dementia (CSDD) [29], and the CohenMansfield Agitation Inventory (CMAI) [30]. 
We did not select CAMDEX and GMS/AGECAT for our pilot as they are predominantly diagnostic tools, irrelevant to our objective. We also did not select AES and GDS as they are self-reported, which is not suitable for our participants. Even though the NPI is a validated clinical tool designed explicitly to provide a comprehensive evaluation of BPSD [31], raters' tight work schedule can deviate the original NPI protocol (e.g., an arbitrary evaluation of symptoms is made based on the general domains instead of using subquestions) [32] or can lead to a possible recall bias (e.g. rating is based on retrospective information [one month]) $[33,34]$. Therefore, considering tight work schedule of LTC staff members and possible recall bias, we did not select NPI.

We selected CSDD as it is feasible for those with advanced dementia [29]. The 19-item CSDD detects depression in dementia, and includes five domains: mood, behaviour, physical signs, cyclic function, and ideation, from interviews with a caregiver [29]. Each item is rated for severity based on symptoms occurring during the week before the interview on a scale of $0-2$ where 0 indicates no symptoms and 2 indicates severe symptoms [29].The interrater reliability $(k=0.67)$ and internal consistency $(a=0.84)$ of the instrument is high [29]. The association between CSDD and Research Diagnostic Criteria Depression (a scale measuring similar construct) also is strong $(r=0.83, p<0.001)$ [29].

We selected 29-item CMAI tool as it is applicable for LTC residents [23]. The CMAI tool assesses the agitated behaviours within four components: 1) Physical Aggressive (PA), 2) Physical Non-Aggressive (PNA), 3) Verbal Aggressive (VA), and 4) Verbal Non-Aggressive (VNA) [30]. Each behaviour is rated on a 7-point scale of frequency, ranging from the resident never manifesting the behaviour (1) to manifesting the behaviour several times an hour (7)[35]. The scale is reliable (test-retest reliability coefficient =0.830; $\mathrm{p}<0.001$ ) [36] in individuals with dementia and has demonstrated construct validity (i.e. strong association with Agitated Behaviour in Dementia, $r=0.62 ; p<0.001$ ) [37].

Sleep disturbance (e.g. difficulty falling asleep, repetitive sleep awakenings, and waking up early) is a risk factor for developing depressive symptoms [38], apathy [39], and aggressiveness [40] in dementia. Sleep disturbance may also indicate comorbidities [41]. The association between sleep disturbance with Pittsburgh Sleep Quality Index [42] and NPI-Apathy domain is moderate $(r=0.38 ; p<0.01)$ [43]. Thus, proportion of night-time sleep indirectly predicts BPSD [43]. Since Henley Place routinely records residents' night-time sleep as a proportion of the total expected asleep time (8 hours, from 10:00 pm to 6:00 am each night), we opted to measure sleep using methods already in place.

We selected DOS [44] as it is designed to be completed by LTC staff members. The scale evaluates objective and accurate data about an individual's behaviour throughout each 24-hour cycle over a period of several consecutive days to identify patterns, trends, contributing factors and modifiable variables associated with BPSD [44]. The rater record duration of observed behaviours (sleeping, awake/calm, positively engaged, repetitive vocal and motor expressions, and sexual/ verbal/physical expression of risk) using number of half an hour blocks and colour codes [44].

We invited the SDM to complete the CSDD, CMAI, and DOS scale. However, the SDM felt that the regular staff (PSW and Registered Practical Nurses [RPN]) could more accurately complete these tools since they 
provide care for the residents 24/7. Caregivers (PSW and RPN) were trained to complete the abovementioned tools. Scales were completed at baseline, at the end of first week, and at the end of second week of therapy. The PI extracted from their medical chart the participants' proportion of night-time sleep at baseline, at the end of first week, and at the end of second week of therapy.

Sensitivity to change of a tool is its ability to detect change (signal over noise) regardless of whether the change is meaningful to the clinician or decision maker [45]. The most appropriate statistic for sensitivity to change remains a matter of debate [46]. Usually, for a single group index, sensitivity to change is reported using Standardized Response Mean (SRM) or ES [47]. The SRM or ES analysis is based on the assumption that the participants are homogenous at the baseline and may exhibit a change by approximately the same amount over the study period [48]. The SRM refers to the ratio of mean change scores $(\delta x=x 2-x 1)$ to the Standard Deviation (SD) of change scores (SD $\delta x)$ [49]. The ES is expressed using a ratio of mean change scores $(\delta x=x 2-x 1)$ to the SD of the baseline scores [49]. For both statistics, if change has occurred, a value greater than 1.0 indicates that the instrument is sensitive to change. We selected ES to report the sensitivity to change as ES to determine the sample size [49] for future research and to facilitate comparison between studies in future meta-analyses [50].

To address objective 5, we explored the association of pre-to post change scores between week 1 and preintervention and again between week 2 and week 1 for the CSDD and CMAI with the GRC using Pearson's $r$ (rho) or coefficient $r$ on SPSS $\odot$ version 26. The GRC scale captures an individual's perspective (in this case, participants' caregivers) regarding their change in health condition (in this case, depression and agitation) [51]. The scale quantifies the change (from a small, unimportant change to a very great deal of change) using scores 0 to 7 ( $0=$ no change, +1 to $+7=$ a perceived improvement in condition, and -1 to $-7=$ a perceived deterioration in condition) [51]. We classified GRC as a lot worse (GRC=-7), moderately worse $(G R C=-4,-5)$, minimally worse $(G R C=-1,-2,-3)$, stable $(G R C=0)$, minimally better $(G R C=1,2,3)$, moderately better $(G R C=4,5)$, and a lot better $(G R C=6,7)$. We had two outliers for GRC-depression $(G R C=-4[n=1]$ at the end of the first week and $G R C=7[n=1]$ at the end of the second week). On the same note, we had one outlier for GRC-agitation ( $G R C=-4[n=1]$ at the end of first week and second week).

To demonstrate longitudinal construct validity, we expected that a GRC rating of 0 would be associated with little to no change in the CSDD/CMAI (i.e. a change score of 0 ). Considering the short period of intervention (two weeks), we did not expect many participants to experience very large changes, thereby reducing the breadth of the scale and reducing the magnitude of the association. Thus, our a priori hypothesis for the correlation between CSDD/CMAI and GRC was weak to moderate. The categorization of the strength of correlation using coefficient $r$ was strong when $r \geq 0.6$, moderate when $r=0.3$ to 0.6 , and weak when $r \leq 0.3$ [49].

\section{Sample Size}

We felt that approximately $15 \%$ of participants would be eligible and have an SDM willing to provide consent to participate in the trial. The reason for our low estimate was that attempts to contact the SDM were to take place during Holiday season (Christmas and New Year), which did not optimize access. To 
maximize the recruitment, RA contacted SDM on weekdays from 9 to 5 and kept the study phone open on evenings and weekends for them to call back. The RA also went into Henley Place after hours to meet SDM in the evenings and weekends. Given this estimate, to be $95 \%$ confident that between $70 \%$ and $100 \%$ of eligible participants (and their SDM) in the population would provide consent, we needed 22 participants [52].

\section{Results}

Figure 2 (The flow chart for participant enrollment, allocation, follow-up, and analysis) describes the number of eligible participants who were approached, screened, signed/withdrew informed consent, received/not received the intervention, lost to follow up/discontinued, and analyzed, describing the reasons for each one.

Six participants failed the screening due to a change of their health condition (CPS score $>5$ [ $n=2$ ], epilepsy [ $n=1]$, palliative care [ $n=1]$, blind [ $n=1]$, unable to communicate in English language [ $n=1])$. One participant withdrew consent before the intervention started due to a conflicting family visit schedule. The demographic and clinical characteristics of the participants are shown in Table 1.

Objective 1. The recruitment rate was (31/77) $40 \%$ (95\% Confidence Interval [CI], $29 \%$ to $52 \%$ ), the adherence rate was (5/24) $21 \%(95 \% \mathrm{Cl}, 7 \%$ to $42 \%)$, and the attrition was $(0 / 24) 0 \%(95 \% \mathrm{Cl}, 0 \%$ to $14 \%)$.

Objective 2. a) $75 \%$ of participants were able to complete at least $80 \%$ of the sessions. The maximum number of sessions attended by any participant was 10 and the minimum number of sessions attended by any participant was 2 .

b) The average length of participants' VR experience was 22.2 ( $95 \% \mathrm{Cl}, 23.5$ to 20.9 ) minutes per session. The shortest length of a session was 1 minute; this participant was agitated when session started and left the intervention area.

c) The observed negative behaviours were complaining $(n=6)$, restlessness $(n=5)$, agitation $(n=2)$, calling out for help $(n=2)$, and crying $(n=1)$. Sixteen $(66 \% ; 95 \% \mathrm{Cl}, 45 \%$ to $84 \%)$ of the 24 participants experienced at least one negative behaviour and $5 / 24(21 \% ; 95 \% \mathrm{Cl}, 7 \%$ to $42 \%)$ participants experienced more than one negative behaviour.

d) The observed positive behaviours were sleeping $(n=24)$, interacting with VR images/RA/PI $(n=19)$, smiling $(n=12)$, singing/humming $(n=5)$, dancing/ tapping feet in rhythm $(n=4)$, and kissing RA's/PI's hand $(n=2)$. All (100\%) participants experienced at least one positive behaviour and $23 / 24$ (96\%; $95 \% \mathrm{Cl}, 79 \%$ to $100 \%)$ participants experienced more than one positive behaviour.

e) All AE were observed outside the VR sessions and were not related to the intervention. We noted five AE during the two-week intervention period; falls $(n=2)$, respiratory tract infection $(n=1)$, loose stool $(n=1)$, and urinary tract infection $(n=1)$. 
f) Overall, the pilot participants were relatively stable since none of them were transferred to emergency four weeks before, during, and after the intervention period. None of them used one-to-one staff four weeks before and during the intervention period. However, three participants used one-to-one staff service after the intervention ( $3 / 24,13 \% ; 95 \% \mathrm{Cl}, 3 \%$ to $32 \%$ ) (at post intervention week 2,1 participant, at post intervention week 3, 2 participants, and at post intervention week 4, 3 participants). The dosage of psychotropic drugs remained either unchanged $(14 / 24,58 \% ; 95 \% \mathrm{Cl}, 37 \%$ to $78 \%)$ or reduced $(8 / 24,33 \%$; $95 \% \mathrm{Cl}, 16 \%$ to $55 \%)$ after the intervention. $11 / 24(46 \% ; 95 \% \mathrm{Cl}, 26 \%$ to $67 \%)$ participants received either an anti-psychotic (Quetiapine) or an anxiolytic (Lorazepam) at baseline. The dose of the antipsychotic was reduced in two of them after the intervention $(2 / 24,8 \% ; 95 \% \mathrm{Cl}, 1 \%$ to $27 \%)$. Anti-depressants were prescribed to $22 / 24(92 \% ; 95 \% \mathrm{Cl}, 73 \%$ to $99 \%)$ participants at baseline and the drug dosage was reduced in six participants $(25 \% ; 95 \% \mathrm{Cl}, 10 \%$ to $47 \%)$ after the intervention. One participant received a new antidepressant (Citalopram) after the intervention ( $4 \% ; 95 \% \mathrm{Cl}, 0 \%$ to $21 \%)$. The frequencies and proportions by EQ-5D dimensions and level indicate no detectable change in participants' health condition from baseline to end of second week of intervention (Table 2). The EQ-5D index value using Crosswalk value set for North America (https://euroqol.org/eq-5d-instruments/eq-5d-5l-about/valuation-standard-valuesets/crosswalk-index-value-calculator/) based on van Hout and colleagues' [53] work also indicates no detectable change in their health condition (index value mean for EQ-5D $\pm S D$ at baseline $=0.4 \pm 0.2$; at week $-1=0.4 \pm 0.3$; and at week-2 $=0.4 \pm 0.3$ ).

Objective 3. a) The order of instances a library item was selected, from most selected to least selected were Cherry Blossom (an afternoon stroll in the park with blooming cherry flowers set to soft classical music) (127 times), Farm (morning walk in a farmyard with cows and chicken set to animal and bird sound) (61 times), Truck driving (day time simulated driving in the country roads) (34 times), Symphony (a concert playing classical music) (32 times), London, UK (aerial view of city streets and iconic building in London, UK set to soft classical music) (30 times), Bavarian Alps (a morning stroll in the alpine meadow set to bird sound) (15 times), Fishing (simulated fishing in the river set to water sound) (13 times), Dolphin Swim club (simulated under water diving set to water sound) (8 times), Ireland (aerial view of city streets and iconic building in Ireland set to soft classical music) (4 times). The following library items were selected $<3$ times each; Boat ride, Dream beach, Park, Sun and clouds, Portugal, Joy ride, and New York.

b) SDM were present in 2 out of 192 sessions.

c) The factors enabling participants' VR experience included: 1) use of Broomx® projector instead of headset, 2) the physical proximity of a familiar individual during VR therapy sessions (PI/RA sitting beside the participant, holding his/her hand), 3) a sound proof room with no visual distractions (e.g. windows, furniture, wall decorations), 4) having the VR set up and running prior to introducing the resident into the intervention area, and 5) knowledge of participants' preferences/dislikes on VR library items. For instance, the library item, Bavarian Alps, brought back traumatic World War 2 memories in a participant; the water themed library items (Dolphin Swim club, Fishing, and Boat ride) frightened a participant; and the Sun and Clouds library item reminded a participant of her departed husband. Avoiding these themes 
improved their attendance at VR sessions. Library items such as Farm and Truck Driving improved five participants' attendance as they felt a personal connection (used to be farmers/ grew up on a farm or used to drive Harley Davidson motorcycle).

d) The factors that negatively affected the participants' VR experience included: 1) interrupted internet (Wi-Fi) connection, 2) VR volume too high, 3) auditory distractions like the sound of closing doors and conversations among the staffs and other residents in the hallway, 4) participants' conflicting schedule, and 5) a negative emotional state of the participant (a participant missed five sessions as his ex-wife accompanied him to the intervention area against his will. Once, the ex-wife stopped accompanying him, he continued VR sessions).

Objective 4. Table 3 and 4 illustrate the mean scores with SD, score difference, and sensitivity to change of CSDD, CMAl, and proportion of night-time sleep to VR therapy. Overall, the selected tools were sensitive to change. A small clinically meaningful change was observed in CMAl score. We also observed small to moderate clinically meaningful negative change in proportion of night-time sleep. Reporting of the DOS was inconsistent with a large proportion of missing data. We, therefore, chose not to report the results.

Objective 5. We observed a weak association between GRC and CSDD/CMAI score confirming our a priori hypothesis. The domain specific association revealed a moderate association in certain domains (the behavioural disturbance domain of CSDD and the verbal aggressive/non-aggressive domain of CMAI). However, the mean change per domain did not equal zero when the GRC indicated no change as per our expected pattern of association (Table 5 and 6 ).

\section{Discussion}

Overall, this pilot shows feasibility and tolerability of VR therapy in LTC homes. Our selected tools were sensitive to change, even given the small intervention time. Particular domains of CSDD and CMAI had moderate association with GRC; demonstrating longitudinal construct validity.

Our intervention period was only two weeks (10 sessions). Five participants missed therapy sessions during the first week due to their conflicting schedule and health condition. A longer (four weeks) and flexible (seven days a week) intervention period might have improved the adherence rate. Furthermore, use of headset, intermittent Wi-Fi network and absence of a suitable intervention area also affected the adherence rate.

We noted that participants' sleep either deteriorated $(n=12)$, remained the same $(n=9)$, or improved $(n=$ 3 ) during the two-week intervention period. Half (6/12) of those with worsening sleep were prescribed psychotropic drugs such as Citalopram, Escitalopram, and Sertraline known for causing insomnia or sleeplessness [54]. Two thirds (2/3) of participants showing improved sleep were prescribed sleepinducing drugs (Trazodone, Mirtazapine) [54]. Almost half (4/9) of the participants who did not have any change in sleep were prescribed combination drugs (Citalopram + Trazodone; and Escitalopram + 
Mirtazapine) known to induce both insomnia and sleep [54]. Therefore, we are unsure if the use of psychotropic drugs reflects an improvement or deterioration of the proportion of sleep.

In EQ-5D domain specific responses, we observed that participants either remained same (Mobility [M], $n$ = 15; Self-Care [SC], $n=13$; Pain/Discomfort [P/D], $n=11$; Anxiety/Depression [A/D], $n=10$; and Usual Activities [UA], $n=7$ ), better (UA, $n=12 ; S C, n=8 ; A / D, n=8 ; P / D, n=5$; and $M, n=4)$, or worse (P/D, $n=8$; $A / D, n=6 ; U A, n=5 ; M, n=5$; and $S C, n=3$ ) after the second week of intervention indicating an overall tendency towards remaining the same. We noted that the participants with improved sleep $(n=3)$ also reported being better in EQ-5D-UA domain after the second week. However, those having deteriorated sleep $(n=8)$ also reported being better in EQ-5D-A/D $(n=5), U A(n=4), S C(n=3)$, and P/D $(n=2)$ domains. Therefore, we are unsure if EQ-5D responses agree with participants' proportion of sleep.

We noticed that more than half $(15 / 24)$ of the participants had an improvement in CSDD score. However, those showing an improvement in CSDD score $(n=8)$ also reported being worse in domain specific EQ-5D responses (A/D [n=4], UA [n=4], P/D [n=4], M [n=2], and SC [n=2]). Furthermore, those having a decline in their proportion of sleep $(n=7)$ showed an improvement in CSDD score. Therefore, we are unable to declare if the change of CSDD score reflects participants' proportion of sleep or EQ-5D responses after the intervention.

The CMAI domain specific changes from baseline to the end of the two-week intervention period showed either an improvement (PNA [ $n=14]$, VNA [ $n=10], P A[n=9], V A[n=8])$, no change (PA [ $=10], V A[n=9]$, VNA [ $[=6]$, PNA [ $n=3]$ ), or deterioration (VNA [n= 8], VA [n=7], PNA [n=7], PA [n=5]) indicating an overall tendency towards improved BPSD with VR therapy. On the other hand, participants having a deteriorated sleep $(n=9)$ had improvement in CMAI domains (PA [ $n=5]$, PNA [ $n=9]$, VA [ $n=5]$, VNA [ $n=6])$. We also noticed that those participants reporting being same in EQ-5D-M $(n=8)$, EQ-5D-SC $(n=7), E Q-5 D-U A(n=$ 4), EQ-5D-P/D ( $n=7)$, and EQ-5D-A/D $(n=9)$ deteriorated in different CMAl domains. Thus, we cannot comment whether a change in CMAl score matches participants' proportion of sleep or their EQ-5D responses.

A recent literature review on potential benefits of VR therapy concluded that such a therapy may provide an opportunity to enjoy leisurely activities that may promote quality of life, psychological well-being, and social interaction in people with dementia without leaving their home [55]. They located nine studies of varying study designs and durations [55]. The common barriers in VR use across the studies were confusion $(n=3)$, discomfort associated with headset $(n=2)$, sadness $(n=1)$, tiredness $(n=1)$, and difficulty with the technology $(n=1)$. We encountered similar barriers in our pilot study, however we were able to propose and test solutions including using projector instead of a head set, consulting with SDM to help identify content most likely to be appealing, paying particular attention to immediate reaction to VR content and making changes as necessary, setting up the VR machine early, and using a dedicated intervention area.

A mixed-method pilot study $(n=10)$ evaluated the effects of VR experience on the level of engagement, apathy, and mood states of people with dementia from two LTC homes [56]. The VR therapy was 15 
minutes in length and was experienced once [56]. The sensitivity to change of Person-Environment Apathy Rating (apathy) $(E S=0.1)$ was trivial [56]. They evaluated participants' engagement interviewing their caregivers [56]. The study reported environmental distractions (noise, cluttered space) as a potential barrier in implementing VR therapy [56] confirming our findings.

A feasibility study on VR therapy for people with dementia $(n=57)$ visiting a memory clinic asked the participants rate their VR experience [57]. The participants reported that they felt secure, comfortable, less anxious, and less fatigued in VR environment [57], which is similar to our experience.

A case study with a 74-year-old male having mild cognitive impairment used VR therapy with headset to evaluate any change in his cognitive status [58]. The participant received VR therapy (building a house in a virtual world) for 45-minutes a day, three times per week for seven consecutive weeks [58]. The participant's caregiver reported that his activities of daily living, his orientation skills during travel, and his mood were improved during the VR therapy [58]. The caregiver also reported cybersickness with the headset [58]. Since our participants had no adverse event related to VR therapy, it may be reasonable to assume that VR therapy using a projector instead of a headset is better tolerated or that the symptom (cybersickness) is rare.

Individuals with a visual impairment and non-English speakers were not eligible for this pilot. However, after observing our pilot participants, we felt that individuals with a visual impairment might also appreciate the advantages of VR therapy through auditory sensation. Further, having music/image-based VR therapy, participants need not be capable of communicating in English to appreciate the effects.

Because of the short length of our therapy, we did not expect to observe a large change in most individuals. Our objective was only to understand whether our proposed instruments can detect change when even a small change has occurred. In fact, when we apply the thresholds described by other authors $[59,60]$ as clinically meaningful, we observed a small clinically meaningful change in CMAl score and in proportion of night-time sleep.

We found a low rate of completion for DOS scale, likely because it was not part of regular required reporting and is conceptually difficult to complete. Therefore, we do not recommend using this tool in a larger trial. We acknowledge that LTC homes collect residents' health related data using Resident Assessment Instrument-Minimum Data Set (RAI-MDS) 2.0 as part of their usual reporting to guide their care planning and monitoring [61]. The RAI-MDS 2.0 collects residents' data on accidents, behavioural and emotional patterns, clinical management, cognitive patterns, elimination and continence, infection control, nutrition and eating, physical functioning, psychotropic drug use, quality of life, and skin care [61]. The RAI-MDS 2.0 components for evaluating BPSD are 1) the Depression Rating Scale (DRS) and 2) the Aggressive Behaviour Scale (ABS) [62]. The DRS evaluates depression using seven items (negative statements, persistent anger with self or others, verbal/non-verbal expressions of unrealistic fear, repetitive health/ non-health complaints, sad/pained/worried facial expression, and crying/tearfulness) scoring 0 to $2(0=$ no symptoms in last 30 days, $1=$ symptoms present five days a week, 2 = symptoms present six/seven days a week) [63]. The scale adds all seven items to provide a final score where 0 
indicates no symptoms and 3 indicates mild depression [63]. The DRS is reliable $(a=0.69)$ and valid (correlation with CSDD [ $r=0.69, p<0.01]$ and Hamilton Depression Rating Scale [64] $[r=0.70, p<0.0]$ is strong) [63]. The ABS has four components (verbal abuse, physical abuse, socially disruptive behaviour, and resistance of care) with a score range from 0-12 (higher scores indicates greater frequency and diversity of aggressive behaviour) [65]. The scoring of ABS is based on seven days' observation of residents where each item is scored from 0 to $3(0=$ no symptoms, $1=$ symptoms observed $1-3$ days in the past 7 days, 2 = symptoms observed $4-36$ days in the past 7 days) [65]. The tool is reliable $(a=0.8)$ and valid (correlation with CMAl is strong, $r=0.72, P<0.01$ ) [66]. The Ministry of Health and Long-Term Care recommends using RAI-MDS 2.0 in Canadian LTC homes [62]. We suggest using RAI-MDS 2.0 in future studies to measure BPSD to avoid redundancy.

\section{Limitations}

The participant recruitment depended on communication with their SDM. The recruitment phase was short (around six weeks) and required us to reach the SDM during their occasional visit to the Henley Place or over the phone only during weekdays from 9 to $5 \mathrm{pm}$. In a fully funded study, with greater resources to allocate to recruitment efforts, we expect recruitments rates to improve.

The clinical utility of the CSDD is highly questionable in identifying depression when administered by LTC staff because of the complexity of the scale, the time and skills required for collecting data, and knowledge of assessing depression [67]. Further, the creators of the CSDD recommend standardized training, which reduces its utility in a practice setting.

Overall, our study was biased inherent to the study design. For example, absence of a control group impaired our ability to report whether changes in outcome reflected the therapy or simply the ups and downs associated with dementia progression.

The study recruited typical Ontario LTC population and the researchers did not require specialization for setting up and conducting VR stimulation therapy. Therefore, this study was pragmatic in nature and likely to be applicable in Ontario LTCs.

\section{Conclusion}

VR therapy is feasible in Ontario LTC homes and residents with moderate to severe dementia might tolerate such therapy. The sensitivity to change of the selected tools (CSDD and CMAI) indicated that VR therapy might have a role in reducing BPSD in the population of interest. However, we are not confident of the precision of these estimates because this was a small pilot study. Considering the burden of BPSD on older adults with dementia and their caregivers, VR therapy is a possible non-pharmacotherapy in managing BPSD in LTC homes.

\section{Abbreviations}


ABS

Aggressive Behaviour Scale

A/D

Anxiety/Depression

$A E$

Adverse Events

AES

Apathy Evaluation Scale

AGECAT

Automated Geriatric Examination for Computer Assisted Taxonomy

BPSD

Behavioural and Psychological Symptoms of Dementia

BSO

Behavioural Supports Ontario

CAMDEX

Cambridge Mental Disorders of the Elderly Examination

$\mathrm{Cl}$

Confidence Interval

CMAI

Cohen-Mansfield Agitation Inventory

CPS

Cognitive Performance Scale

CSDD

Cornell Scale for Depression in Dementia

DOS

Dementia Observation System

DRS

Depression Rating Scale

EQ-5D

Euro-Qol 5-Dimention

ES

Effect Size

GDS

Geriatric Depression Screening scale

GMS

Geriatric Mental State Schedule

GRC

Global Rating of Change

LTC

Long-Term Care 
Mobility

NPI

Neuro Psychiatric Inventory

PA

Physical Aggressive

$P / D$

Pain/Discomfort

$\mathrm{PI}$

Principal Investigator

PNA

Physical Non-Aggressive

PSW

Personal Support Workers

RA

Research Assistant

RAI-MDS

Resident Assessment Instrument-Minimum Data Set

RPN

registered practical nurses

SC

Self-Care

SD

Standard Deviation

SDM

Substitute Decision-Maker

SRM

Standardized Response Mean

UA

Usual Activities

VA

Verbal Aggressive

VNA

Verbal Non-Aggressive

VR

Virtual Reality

Declarations 
Ethics approval and consent to participate: The study was ethically approved by ADVARRA Canada Ethics board. The protocol number of this study is Pro00030688. The protocol can be accessed on https://www.cirbi.net with permission from the sponsor (primacare Living Solutions Inc. TM).

Consent for publication: All authors consent for publication and declare no conflict of interest.

Availability of data and material: Data and materials can be accessed on

http://www.empowerhealthresearch.ca/ with permission from the sponsor (primacare Living Solutions Inc. ${ }^{T M}$ ) but restrictions apply to the availability of these data, which were used under license for the current study, and so are not publicly available. Data are however available from the authors upon reasonable request and with permission of primacare Living Solutions Inc. ${ }^{\mathrm{TM}}$.

Competing interests: Coauthor Dr. Manuel Montero-Odasso is an Editorial Board Member.

Funding. The study was funded by nonprofit external grant from the Centre for Aging and Brain Health Innovation as part of the Industry Innovation Partnership Program (I2P2) to the partners primacare Living Solutions Inc. ${ }^{\mathrm{Tm}}$ and Crosswater Digital Media, LLC. The funders supplied Broomx@ (hardware and software) and paid the research staff for their time; the partner, primacare Living Solutions Inc. ${ }^{\mathrm{TM}}$, provided space for the therapy, access to residents' medical charts, and their staff in communicating, transferring, accompanying the participants, and completing the outcome measures; and the other partner, Crosswater Digital Media, LLC., created library items for this study.

Authors' contributions: MS analyzed and interpreted data, written the manuscript, and revised it critically for important intellectual content; KC designed and conducted the pilot study, and contributed in revising the manuscript; $\mathrm{MJ}$ contributed in analysis, interpretation of data, and critical revision for the work. MMO and JBO contributed in interpretation of data and revision of the manuscript; JK contributed in conception, design, and critical revision for the work; ASG created VR library for this project; and DB contributed in design, analysis, interpretation, and critical revision for important intellectual content. All authors are in agreement to be accountable for all aspects of the work in ensuring that questions related to the accuracy or integrity of any part of the work are appropriately investigated and resolved.

Acknowledgements. Authors would like to acknowledge primacare Living Solutions Inc. ${ }^{\mathrm{T}}{ }^{\mathrm{T}}$ for allowing access to study protocol and data.

\section{References}

1. National Institute for Health and Care Excellence. Falls in older people: Assessing risk and prevention. 2013. https://www.nice.org.uk/guidance/cg161/resources/falls-in-older-people-assessing-risk-andprevention-35109686728645 Accessed on 6 Jan 2020.

2. Public Health Agency of Canada. Dementia in Canada, including Alzheimer's disease. 2017. https://www.canada.ca/en/public-health/services/publications/diseases-conditions/dementiahighlights-canadian-chronic-disease-surveillance.html Accessed on 6 Jan 2020. 
3. Public Health Agency of Canada. The national population health study of neurological conditions. 2012. https://www.canada.ca/en/public-health/services/reports-publications/mapping-connectionsunderstanding-neurological-conditions/mapping-connections-understanding-neurological-conditionscanada-13.html\#tab3-7 Accessed on 6 Jan 2020.

4. Nichols E, Szoeke CEl, Vollset SE, Abbasi N, Abd-Allah F, Abdela J, et al. Global, regional, and national burden of Alzheimer's disease and other dementias, 1990-2016: A systematic analysis for the global burden of disease study 2016. Lancet Neurol. 2019; DOI:10.1016/S1474-4422(18)30403-4

5. Hay S, Abajobir AA, Abate KH, Abbafati C, Abbas KM, Abd-Allah F, et al. Global, regional, and national disability-adjusted life-years (DALYS) for 333 diseases and injuries and healthy life expectancy (HALE) for 195 countries and territories, 1990-2016: A systematic analysis for the global burden of disease study 2016. Lancet. 2017; DOI:10.1016/S0140-6736(17)32130-X

6. O'Donnell BF, Drachman DA, Barnes HJ, Peterson KE, Swearer JM, et al. Incontinence and troublesome behaviours predict institutionalization in dementia. J Geriatr Psych Neur.1992; 5:1. 4552.

7. Lyketsos CG, Lopez O, Jones B, Fitzpatrick AL, Breitner J, DeKosky S. Prevalence of neuropsychiatric symptoms in dementia and mild cognitive impairment: Results from the cardiovascular health study. JAMA. 2002; DOI: 10.1001/jama.288.12.1475

8. Yaffe K, Fox P, Newcomer R, Sands L, Lindquist K, Dane K, et al. Patient and caregiver characteristics and nursing home placement in patients with dementia. JAMA. 2002; DOI:

10.1001/jama.287.16.2090

9. Buhr GT, Kuchibhatla M, Clipp EC. Caregivers' reasons for nursing home placement: Clues for improving discussions with families prior to the transition. Gerontologist. 2006; DOI:

10.1093/geront/46.1.52

10. Tible OP, Riese F, Savaskan E, von Gunten A. Best practice in the management of behavioural and psychological symptoms of dementia. Ther Adv Neurol Diso. 2017;

DOI: $10.1177 / 1756285617712979$

11. Corbett A, Husebo B, Malcangio M, Staniland A, Cohen-Mansfield J, Aarsland D, et al. Assessment and treatment of pain in people with dementia. Nat. Rev. Neurosci. 2012; DOI:

10.1038/nrneurol.2012.53

12. Reus VI, Fochtmann LJ, Eyler AE, Hilty DM, Horvitz-Lennon M, Jibson MD, et al. The American Psychiatric Association practice guideline on the use of antipsychotics to treat agitation or psychosis in patients with dementia. Am J Psychiatry. 2016; DOI: 10.1176/appi.ajp.2015.173501

13. Shaji KS, Sivakumar PT, Rao GP, Paul N. Clinical practice guidelines for management of dementia. Indian J. Psychiatry. 2018; 60 Suppl 3: S312. DOI:10.4103/0019-5545.224472

14. Wiederhold BK. Virtual reality enhances seniors' health and well-being. Cyberpsychol Behav Soc Netw. 2018; DOI:10.1089/cyber.2018.29132.bkw

15. The Projected VR Company. BroomxVR. 2019; http://www.broomx.com/broomxvr.php Accessed on 6 Jan 2020. 
16. Canadian Institute for Health Information. Analysis in brief: Caring for seniors with Alzheimer's disease and other forms of dementia. 2010; https://secure.cihi.ca/free_products/Dementia_AIB_2010_EN.pdf Accessed on 6 Jan 2020.

17. Morris JN, Fries BE, Mehr DR, Hawes C, Phillips C, Mor V, et al. MDS Cognitive Performance Scale. J. Gerontol. 1994; 49(4): M174-82.

18. Broomx Technologies. MKplayer360. 2019. http://www.broomx.com/mkplayer360.php Accessed on 6 Jan 2020.

19. Algase D, Beck C, Kolanowski A, Whall A, Berent S, Richards K, et al. Need-driven dementiacompromised behavior: An alternative view of disruptive behavior. Am J Alzheimers Dis Other Demen. 1996; https://doi.org/10.1177/153331759601100603

20. Schulz P, Steimer T. Psychotropic medication, psychiatric disorders, and higher brain functions. Dialogues Clin Neurosci. 2000; 2(3):177-182.

21. EuroQoL Group. EuroQoL: A new facility for the measurement of health-related quality of life. Health Policy. 1990; 16: 199-208.

22. Schrag A, Selai C, Jahanshahi M, Quinn NP. The EQ-5D: A generic quality of life measure is a useful instrument to measure quality of life in patients with Parkinson's disease. $J$ Neurol Neurosurg Psychiatry. 2000; DOI:10.1136/jnnp.69.1.67

23. Linde RM, Stephan BCM, Dening T, Brayne C. Instruments to measure behavioural and psychological symptoms of dementia. Int J Meth Psych Res. 2014; DOl:10.1002/mpr.1414

24. Roth M, Tym E, Mountjoy C, Huppert F, Hendrie H, Verma S, et al. CAMDEX: A standardised instrument for the diagnosis of mental disorder in the elderly with special reference to the early detection of dementia. Br J Psychiatry. 1986; DOI:10.1192/bjp.149.6.698

25. Copeland JR, Kelleher MJ, Kellett JM, Gourlay AJ, Gurland BJ, Fleiss JL, et al. A semi-structured clinical interview for the assessment of diagnosis and mental state in the elderly: The Geriatric Mental State Schedule. I. Development and reliability. Psychol Med. 1976; 6(3): 439-49.

26. Marin RS, Biedrzycki RC, Firinciogullari S. Reliability and validity of the apathy evaluation scale. Psychiatry Res. 1991; DOI:10.1016/0165-1781(91)90040-V

27. Yesavage JA, Brink TL, Rose TL, Lum O, Huang V, Adey M, et al. Development and validation of a geriatric depression screening scale: A preliminary report. J Psychiatr Res. 1982; DOI:10.1016/00223956(82) 90033-4

28. Cummings JL, Mega M, Gray K, Rosenberg-Thompson S, Carusi DA, Gornbein J. The neuropsychiatric inventory: Comprehensive assessment of psychopathology in dementia. Neurology. 1994; 44(12): 2308-14.

29. Alexopoulos GA, Abrams RC, Young RC, Shamoian CA. Cornell Scale for Depression in Dementia. Biol Psychiatry. 1988; 23: 271-84.

30. Cohen-Mansfield J. Agitated behaviours in the elderly: II. Preliminary results in the cognitively deteriorated. JAGS. 1986; 34: 722-7. 
31. Kaufer DI, Cummings JL, Christine D, Bray T, Castellon S, Masterman D, et al. Assessing the impact of neuropsychiatric symptoms in Alzheimer's disease: The neuropsychiatric inventory caregiver distress scale. JAGS. 1998; 46(2): 210-215. DOI:10.1111/j.1532-5415.1998.tb02542.x

32. Connor DJ, Sabbagh MN, Cummings JL. Comment on administration and scoring of the Neuropsychiatric Inventory in clinical trials. Alzheimers Dement. 2008; DOI:

10.1016/j.jalz.2008.09.002

33. Stella F, Forlenza O, Laks J, Andrade L, Avendano M, Cacao ESJC, et al. Validity and reliability of the neuropsychiatric inventory-clinician rating scale (NPI-C)@ in a Brazilian multicenter study: Assessment of neuropsychiatric symptoms in dementia. Alzheimers Dement. 2013; DOI: https://doi.org/10.1016/j.jalz.2013.05.1504

34. Stella F, Forlenza OV, Laks J, Pires de Andrade L, de Castillo Cacao J, Govone JS, et al. Caregiver report versus clinician impressions: Disagreements in rating neuropsychiatric symptoms in Alzheimer's disease patients. Int J Geriatr Psych. 2015; 30,1230-7. DOI: 10.1002/gps.4278

35. Cohen-Mansfield J, Marx MS, Rosenthal AS. Dementia and agitation in nursing home residents: How are they related? Psychology and Aging. 1990; 5(1): 3-8.

36. Koss E, Weiner M, Ernesto C, Cohen-Mansfield J, Ferris SH, Grundman M, et al. Assessing patterns of agitation in Alzheimer's disease patients with the Cohen-Mansfield Agitation Inventory: The Alzheimer's disease cooperative study. Alzheimer Dis Assoc Disord. 1997; 11 Suppl 2: S45-S50.

37. Logsdon RG, Teri L, Weiner MF, Gibbons LE, Raskind M, Peskind E, et al. Assessment of agitation in Alzheimer's disease: The agitated behaviour in dementia scale: Alzheimer's disease cooperative study. JAGS. 1999, 47(11): 1354-1358. DOI: 10.1111/j.1532-5415.1999.tb07439.x

38. Arbus C, Gardette V, Cantet CE, Andrieu S, Nourhashemi F, Schmitt L, et al. Incidence and predictive factors of depressive symptoms in Alzheimer's disease: The REAL.FR study. J Nutr Health Aging. 2011; 15: 609-17. DOI: 10.1007/s12603-011-0061-1

39. Mulin E, Zeitzer JM, Friedman L, Le Duff F, Yesavage J, Robert PH, et al. Relationship between apathy and sleep disturbance in mild and moderate Alzheimer's disease: An actigraphic study. JAD. 2011; 25, 85-91. DOI: 10.3233/JAD-2011-101701

40. Moran M, Lynch CA, Walsh C, Coen R, Coakley D, Lawlor BA. Sleep disturbance in mild to moderate Alzheimer's disease. Sleep Med. 2005; 6: 347-52. DOI: 10.1016/j.sleep.2004.12.005

41. Bubu OM, Brannick M, Mortimer J, Umasabor-Bubu O, Sebastiao YV, Wen Y, et al. Sleep, cognitive impairment, and Alzheimer's disease: A systematic review and meta-analysis. Sleep. 2017; 40(1). doi: 10.1093/sleep/zsw032.

42. Buysse DJ, Reynolds CF, Monk TH, Berman SR, Kupfer DJ. The Pittsburgh sleep quality index: A new instrument for psychiatric practice and research. Psychiatry Res. 1989; 28 (2): 193-213. DOI:10.1016/0165-1781(89)90047-4

43. Shin HY, Han HJ, Shin DJ, Park HM, Lee YB, Park KH. Sleep problems associated with behavioural and psychological symptoms as well as cognitive functions in Alzheimer's disease. J Clin Neurol. 2014; 10(3): 203-09. DOI:10.3988/jcn.2014.10.3.203 
44. DOS Working Group. Behavioural Supports Ontario-Dementia Observation System (BSO-DOS@) resource manual: Informing person and family-centred care through direct observation documentation. Ontario, Canada: Behavioural Supports Ontario Provincial Coordinating Office; 2019. https://brainxchange.ca/Public/BSO/Files/DOS/BSO-DOS-Resource-Manual-FINAL-May-2019.aspx Accessed on 7 Jan 2020.

45. Liang $\mathrm{MH}$. Longitudinal construct validity: Establishment of clinical meaning in patient evaluative instruments. Med Care. 2000; 38: II-84-II-90. DOI:10.1097/00005650-200009002-00013

46. Beaton D, Hogg-Johnson S, Bombardier C. Evaluating changes in health status: Reliability and responsiveness of five generic health status measures in workers with musculoskeletal disorders. J Clin Epidemiol. 1997. 50(1): 79-93. https://doi.org/10.1016/S0895-4356(96)00296-X

47. Finch E, Brooks D, Stratford P. Why measurement properties are important. In Canadian Physiotherapy Association editors. Physical rehabilitation outcome measures: A guide to enhanced clinical decision-making. Ontario, Canada: BC Decker; 2002. p 26-41.

48. Stratford PW, Riddle DL. Assessing sensitivity to change: Choosing the appropriate change coefficient. HQLO. 2005; 3(1): 23. https://doi.org/10.1186/1477-7525-3-23

49. Cohen J. Statistical power analysis for the behavioral sciences. 2nd ed. New Jersey. Hillsdale; 1988.

50. Maxwell SE, Delaney HD. Designing experiments and analyzing data: A model comparison perspective. 2nd ed. NJ: Erlbaum. Mahwah; 2004.

51. Jaeschke R, Singer J, Guyatt GH. Measurement of health status: Ascertaining the minimal clinically important difference. Control Clin Trials. 1989; 10: 407-15. DOI: 10.1016/0197-2456(89)90005-6

52. Dhand NK, Khatkar MS. Statulator: An online statistical calculator: Sample size calculator for estimating a single proportion. 2014. http://statulator.com/SampleSize/ss1P.html Accessed on 7 Jan 2020.

53. van Hout B, Janssen MF, Feng YS, Kohlmann T, Busschbach J, Golicki D, et al. Interim scoring for the EQ-5D-5L: Mapping the EQ-5D-5L to EQ-5D-3L value sets. Value Health. 2012; 15: 708-715. DOI: 10.1016/j.jval.2012.02.008.

54. Goncalves R, Togeiro SMG. Drug-induced sleepiness and insomnia: An update. Sleep Sci. 2012; $6(1): 36-43$.

55. D’Cunha NM, Nguyen D, Naumovski N, McKune AJ, Kellett JK, Georgousopoulou EN, et al. A minireview of virtual reality-based therapy to promote well-being for people living with dementia and mild cognitive impairment. Gerontology. 2019; 65(4): 430-40. DOI: 10.1159/000500040

56. Moyle W, Jones C, Dwan T, Petrovich T. Effectiveness of a virtual reality forest on people with dementia: A mixed methods pilot study. Gerontologist. 2018; 58(3): 478-487.

DOI:10.1093/geront/gnw270

57. Manera V, Chapoulie E, Bourgeois J, Guerchouche R, David R, Ondrej J, et al. A feasibility study with image-based rendered virtual reality in patients with mild cognitive impairment and dementia. PloS One. 2016; 11(3): e0151487. DOI:10.1371/journal.pone.0151487 
58. White PJ, Moussavi Z. Neurocognitive treatment for a patient with Alzheimer's disease using a virtual reality navigational environment. J Exp Neurosci. 2016; 10: 129-35. DOI: 10.4137/JEN.S40827

59. Rapp MA, Mell T, Majic T, Treusch Y, Nordheim J, Niemann-Mirmehdi M, et al. Agitation in nursing home residents with dementia (VIDEANT trial): Effects of a cluster-randomized, controlled, guideline implementation trial. J Am Med Dir Assoc. 2013; 14(9): 690-695. DOI: 10.1016/j.jamda.2013.05.017

60. Perlis M, Aloia M, Millikan A, Boehmler J, Smith M, Greenblatt D, et al. Behavioural treatment of insomnia: A clinical case series study. J Behav Med. 2000; 23(2): 149-161.

DOI:10.1023/A:1005413117932

61. Hutchinson A, Milke D, Maisey S, Johnson C, Squires J, Teare G, et al. The Resident Assessment Instrument-Minimum Data Set 2.0 quality indicators: A systematic review. BMC Health Serv Res. 2010; 10(1). https://doi.org/10.1186/1472-6963-10-166

62. Canadian Institute for Health Information. User guidelines for the job aid: Putting it all together: RAIMDS( and P.I.E.C.E.S. ${ }^{\mathrm{TM}}$ integration. 2010. https://brainxchange.ca/Public/Files/Psychogeriatric/User-Guidelines-RAI-MDS-PIECES.aspx Accessed on 7 Jan 2020.

63. Burrows A, Morris JN, Simon S, Hirdes JP, Phillips C. Development of a Minimum Data Set-based Depression Rating Scale for use in nursing homes. Age Ageing. 2000; 29(2): 165-172. DOI: 10.1093/ageing/29.2.165

64. Hamilton M. A rating scale for depression. J Neurol Neurosurg Psychiatry. 1960; 23:56-62

65. Orpinas P, Frankowski R. The Aggression Scale: A self-report measure of aggressive behavior for young adolescents. J Early Adolesc. 2001; 21, 50-67. https://doi.org/10.1177/0272431601021001003

66. Perlman C, Hirdes J. The Aggressive Behavior Scale: A new scale to measure aggression based on the Minimum Data Set. JAGS. 2008; 56(12): 2298-2303. https://doi.org/10.1111/j.15325415.2008.02048.x

67. Jeon YH, Li Z, Low L, Chenoweth L, O'Connor D, Beatty E, et al. The clinical utility of the Cornell Scale for Depression in Dementia as a routine assessment in nursing homes. Am J Geriatr Psychiatry. 2015; 23(8): 784-793. DOI: 10.1016/j.jagp.2014.08.013

\section{Tables}

Table 1

The demographic and clinical characteristics of the participants 


\begin{tabular}{|l|l|}
\hline Characteristics of participants & \\
\hline Age (mean, standard deviation [SD]) & $85.8 \pm 8.6$ \\
\hline Sex $(n, \%)$ & Female $(18,75 \%)$ \\
\hline CPS score (mean, SD) & $3.4 \pm 0.6$ \\
\hline Dementia types: & \\
\hline Alzheimer's disease $(\mathrm{n}, \%)$ & $3,12.5 \%$ \\
\hline Unspecified dementia $(\mathrm{n}, \%)$ & $21,87.5 \%$ \\
\hline Comorbidities: & \\
\hline Depression (n, \%) & $21,87.5 \%$ \\
\hline Diabetes mellitus (n, \%) & $3,12.5 \%$ \\
\hline Stroke $(n, \%)$ & $2,8.3 \%$ \\
\hline Concussion $(n, \%)$ & $1,4.2 \%$ \\
\hline
\end{tabular}

Table 2

Distribution of EQ-5D dimension responses at baseline, week 1 and week 2 with index value

\begin{tabular}{|l|l|l|l|l|l|}
\hline $\begin{array}{l}\text { EQ-5D Baseline } \\
\text { profile }\end{array}$ & $\begin{array}{l}\text { EQ-5D Baseline } \\
\text { index value }\end{array}$ & $\begin{array}{l}\text { EQ-5D } \\
\text { Week-1 } \\
\text { rrofile }\end{array}$ & $\begin{array}{l}\text { EQ-5D Week-1 } \\
\text { index value }\end{array}$ & $\begin{array}{l}\text { EQ-5D } \\
\text { Week-2 } \\
\text { profile }\end{array}$ & $\begin{array}{l}\text { EQ-5D Week-2 } \\
\text { index value }\end{array}$ \\
\hline 22432 & 0.6 & 12332 & 0.7 & 12232 & 0.7 \\
\hline 55355 & -0.1 & 55555 & -0.1 & 54334 & 0.2 \\
\hline 55435 & 0.1 & 55511 & 0.2 & 55532 & 0.1 \\
\hline 35322 & 0.4 & 53453 & 0.1 & 53432 & 0.3 \\
\hline 35543 & 0.3 & 44542 & 0.3 & 44453 & 0.3 \\
\hline 15411 & 0.5 & 23333 & 0.6 & 13222 & 0.7 \\
\hline 11121 & 0.7 & 11211 & 0.9 & 11112 & 0.9 \\
\hline 44532 & 0.4 & 45533 & 0.3 & 54221 & 0.3 \\
\hline 23423 & 0.6 & 22121 & 0.8 & 22322 & 0.7 \\
\hline 55511 & 0.2 & 55521 & 0.2 & 55522 & 0.1 \\
\hline 55513 & 0.2 & 55524 & 0.1 & 55332 & 0.2 \\
\hline 15521 & 0.4 & 15534 & 0.3 & 15121 & 0.5 \\
\hline 14411 & 0.7 & 35531 & 0.4 & 25421 & 0.4 \\
\hline 55543 & 0.1 & 55523 & 0.1 & 55544 & 0.0 \\
\hline 24532 & 0.4 & 23321 & 0.7 & 24332 & 0.6 \\
\hline 34433 & 0.5 & 15523 & 0.4 & 24423 & 0.5 \\
\hline 12421 & 0.7 & 12312 & 0.7 & 12121 & 0.8 \\
\hline 25534 & 0.3 & 34332 & 0.6 & 24433 & 0.5 \\
\hline 45523 & 0.3 & 45454 & 0.1 & 55544 & 0.0 \\
\hline 54333 & 0.2 & 55544 & 0.0 & 55432 & 0.2 \\
\hline 23311 & 0.8 & 12321 & 0.8 & 12124 & 0.6 \\
\hline 23244 & 0.4 & 13355 & 0.2 & 24332 & 0.6 \\
\hline 24222 & 0.6 & 13232 & 0.7 & 14322 & 0.7 \\
\hline 25431 & 0.4 & 13221 & 0.8 & 23332 & 0.6 \\
\hline & & & & & \\
\hline
\end{tabular}


Table 3

Mean scores with standard deviation and pre-post score difference of the outcome measures

\begin{tabular}{|l|l|l|l|l|l|}
\hline Scales & $\begin{array}{l}\text { Baseline } \\
\text { (mean, SD) }\end{array}$ & $\begin{array}{l}\text { Week 1 } \\
\text { (mean, SD) }\end{array}$ & $\begin{array}{l}\text { Week 2 } \\
\text { (mean, SD) }\end{array}$ & $\begin{array}{l}\text { Change (Week 1-Baseline) } \\
\text { (mean, SD) }\end{array}$ & $\begin{array}{l}\text { Change (Week 2-Baseline) } \\
\text { (mean, SD) }\end{array}$ \\
\hline CSDD & $9.7 \pm 5.3$ & $7.5 \pm 4.6$ & $7.5 \pm 4.1$ & $2.2 \pm 6.1$ & $2.1 \pm 4.9$ \\
\hline Mood & $3.0 \pm 1.8$ & $2.4 \pm 1.9$ & $2.5 \pm 1.8$ & $0.5 \pm 2.1$ & $0.5 \pm 1.8$ \\
\hline Behaviour & $2.4 \pm 1.6$ & $1.8 \pm 1.5$ & $1.7 \pm 1.2$ & $0.6 \pm 2.1$ & $0.7 \pm 1.9$ \\
\hline Physical signs & $1.8 \pm 1.3$ & $1.4 \pm 1.0$ & $1.4 \pm 1.2$ & $0.4 \pm 1.3$ & $0.5 \pm 1.4$ \\
\hline Cyclic function & $1.8 \pm 1.7$ & $1.5 \pm 1.6$ & $1.3 \pm 1.3$ & $0.4 \pm 2.2$ & $0.5 \pm 1.7$ \\
\hline Ideation & $0.6 \pm 0.8$ & $0.3 \pm 0.9$ & $0.7 \pm 1.0$ & $0.3 \pm 1.1$ & $0.1 \pm 1.1$ \\
\hline CMAl & $53.3 \pm 19.1$ & $51.3 \pm 21.7$ & $48.8 \pm 17.2$ & $2.3 \pm 13.4$ & $4.8 \pm 15.2$ \\
\hline $\begin{array}{l}\text { Physical } \\
\text { aggressive }\end{array}$ & $18.8 \pm 10.7$ & $17.8 \pm 9.2$ & $16.4 \pm 6.7$ & $1.0 \pm 4.3$ & $2.3 \pm 7.7$ \\
\hline $\begin{array}{l}\text { Physical non- } \\
\text { aggressive }\end{array}$ & $18.3 \pm 6.3$ & $16.5 \pm 6.5$ & $16 \pm 5.8$ & $1.8 \pm 7.1$ & $2.3 \pm 6.5$ \\
\hline $\begin{array}{l}\text { Verbal } \\
\text { aggressive }\end{array}$ & $6.4 \pm 4.3$ & $6.5 \pm 4.6$ & $5.9 \pm 3.1$ & $0.1 \pm 2.8$ & $0.5 \pm 3.2$ \\
\hline $\begin{array}{l}\text { Verbal non- } \\
\text { aggressive }\end{array}$ & $10.2 \pm 6.3$ & $10.6 \pm 8.2$ & $10.7 \pm 7.1$ & $0.4 \pm 5.9$ & $0.5 \pm 5.7$ \\
\hline \begin{tabular}{l} 
Sleep \\
\hline
\end{tabular} & $94.3 \pm 9.1$ & $88.3 \pm 17.5$ & $89.3 \pm 16$ & $5.9 \pm 13.3$ & $5.1 \pm 10.2$ \\
\hline
\end{tabular}

CSDD $=$ Cornell Scale for Depression in Dementia, CMAI= Cohen-Mansfield Agitation Inventory, SD=Standard Deviation

Table 4

Pre-post sensitivity to change of the outcome measures size of response, and clinical importance 


\begin{tabular}{|l|l|l|l|}
\hline Scales & $\begin{array}{l}\text { ES (Week 1- } \\
\text { Baseline) }\end{array}$ & $\begin{array}{l}\text { ES (Week 2- } \\
\text { Baseline) }\end{array}$ & Clinically meaningful (at 2 weeks only) \\
\hline CSDD & 0.4 & 0.4 & Yes (small) \\
\hline Mood & 0.3 & 0.3 & Yes (small) \\
\hline Behaviour & 0.4 & 0.4 & Yes (small) \\
\hline Physical signs & 0.3 & 0.4 & Yes (small) \\
\hline Cyclic function & 0.2 & 0.3 & Yes (small) \\
\hline Ideation & 0.3 & 0.1 & Yes (trivial) \\
\hline CMAl & 0.1 & 0.2 & Yes (small), Clinically meaningful \\
\hline Physical aggressive & 0.1 & 0.2 & Yes (small) \\
\hline $\begin{array}{l}\text { Physical non- } \\
\text { aggressive }\end{array}$ & 0.3 & 0.4 & Yes (small) \\
\hline Verbal aggressive & 0.02 & 0.1 & Yes (trivial) \\
\hline $\begin{array}{l}\text { Verbal non- } \\
\text { aggressive }\end{array}$ & 0.01 & 0.1 & Yes (trivial) \\
\hline \begin{tabular}{l} 
Sleep \\
\hline
\end{tabular} & 0.7 & 0.6 & $\begin{array}{l}\text { Yes (small to moderate), Clinically } \\
\text { meaningful }\end{array}$ \\
\hline
\end{tabular}

CSDD = Cornell Scale for Depression in Dementia, CMAI= Cohen-Mansfield Agitation Inventory, ES=Effect Size.

According to Cohen an ES is trivial if it is less than 0.20 , small if it is between $0.21-0.49$, moderate if it is between $0.51-0.79$, and large if it is greater than 0.80 (Cohen, 1988). We considered the change to be clinically meaningful when ES of CMAI score was $\geq 0.2$ (Rapp et al., 2013), and ES of sleep percentage was $\geq 0.4$ (Perlis et al., 2000).

Table 5

Longitudinal validity of Cornell Scale for Depression in Dementia domains at the end of week 1 and week 2 


\begin{tabular}{|c|c|c|c|c|}
\hline CSDD domain & \multicolumn{4}{|c|}{ GRC-depression } \\
\hline \multirow[t]{2}{*}{$\mathrm{N}=24$} & \multicolumn{4}{|l|}{ Week 1} \\
\hline & $\begin{array}{l}\text { Pearson } \\
\text { correlation }\end{array}$ & $\begin{array}{l}\text { Moderately better }(4,5)(n=5) \\
(\text { mean } \pm S D)\end{array}$ & $\begin{array}{l}\text { Minimally better }(1,2,3) \quad(n=2) \\
\text { (mean } \pm S D)\end{array}$ & $\begin{array}{l}\text { Stable }(0)(n=16) \\
(\text { mean } \pm S D)\end{array}$ \\
\hline Total score & -0.23 & $6.6 \pm 5.5$ & $6 \pm 1.4$ & $7.5 \pm 4.6$ \\
\hline $\begin{array}{l}\text { Mood-related } \\
\text { signs }\end{array}$ & -0.15 & $2.4 \pm 2$ & $2 \pm 1.4$ & $2.3 \pm 1.9$ \\
\hline $\begin{array}{l}\text { Behavioural } \\
\text { disturbance }\end{array}$ & -0.28 & $1.2 \pm 1.1$ & $1 \pm 1$ & $2 \pm 1.6$ \\
\hline Physical signs & -0.05 & $4.2 \pm 0.5$ & $2.5 \pm 0.7$ & $1.4 \pm 1$ \\
\hline Cyclic functions & -0.22 & $1.2 \pm 1.1$ & $1 \pm 0.0$ & $1.4 \pm 1.8$ \\
\hline \multirow{3}{*}{$\begin{array}{l}\text { Ideational } \\
\text { disturbance }\end{array}$} & 0.02 & $0.4 \pm 0.9$ & $0.0 \pm 0.0$ & $0.4 \pm 1.0$ \\
\hline & \multicolumn{4}{|l|}{ Week 2} \\
\hline & $\begin{array}{l}\text { Pearson } \\
\text { correlation }\end{array}$ & $\begin{array}{l}\text { Moderately better }(4,5)(n=5) \\
(\text { mean } \pm S D)\end{array}$ & $\begin{array}{l}\text { Minimally better }(1,2,3)(n=4) \\
(\text { mean } \pm S D)\end{array}$ & $\begin{array}{l}\text { Stable }(0)(n=14) \\
(\text { mean } \pm S D)\end{array}$ \\
\hline Total score & -0.16 & $5.2 \pm 3.3$ & $9 \pm 3.6$ & $7.9 \pm 4.5$ \\
\hline $\begin{array}{l}\text { Mood-related } \\
\text { signs }\end{array}$ & -0.09 & $1.8 \pm 1.6$ & $2.8 \pm 1.7$ & $2.6 \pm 2$ \\
\hline $\begin{array}{l}\text { Behavioural } \\
\text { disturbance }\end{array}$ & -0.25 & $1 \pm 0.7$ & $1.5 \pm 1.3$ & $2 \pm 1.4$ \\
\hline Physical signs & -0.08 & $1 \pm 1$ & $2 \pm 1.2$ & $1.4 \pm 1.3$ \\
\hline Cyclic functions & 0.07 & $1 \pm 1$ & $2 \pm 1.2$ & $1.2 \pm 1.4$ \\
\hline $\begin{array}{l}\text { Ideational } \\
\text { disturbance }\end{array}$ & -0.18 & $0.4 \pm 0.9$ & $0.8 \pm 1$ & $0.8 \pm 1.1$ \\
\hline
\end{tabular}

$\mathrm{CSDD}=$ Cornell Scale for Depression in Dementia, $\mathrm{GRC}=$ Global Rating of Change, $\mathrm{SD}=$ Standard Deviation

Table 6

Longitudinal validity of Cohen-Mansfield Agitation Inventory domains at the end of week 1 and week 2 


\begin{tabular}{|c|c|c|c|c|c|}
\hline CMAI domain & & \multicolumn{4}{|l|}{ GRC-agitation } \\
\hline \multirow[t]{2}{*}{$\mathrm{N}=24$} & \multicolumn{5}{|l|}{ Week 1} \\
\hline & $\begin{array}{l}\text { Pearson } \\
\text { correlation }\end{array}$ & $\begin{array}{l}\text { Moderately better }(4,5) \\
(n=2)(\text { mean } \pm S D)\end{array}$ & $\begin{array}{l}\text { Minimally better }(1,2,3) \\
(n=8)(\text { mean } \pm S D)\end{array}$ & $\begin{array}{l}\text { Stable (0) } \\
(n=10) \text { (mean } \\
\pm S D)\end{array}$ & $\begin{array}{l}\text { Minimally worse }(-1,-2 \text {, } \\
-3)(n=3)(\text { mean } \pm S D)\end{array}$ \\
\hline Total score & -0.16 & $53.5 \pm 7.8$ & $48.9 \pm 19.6$ & $42.5 \pm 19.4$ & $80 \pm 13.5$ \\
\hline $\begin{array}{l}\text { Physical } \\
\text { aggressive }\end{array}$ & -0.15 & $16 \pm 7.1$ & $17.5 \pm 10.0$ & $16.7 \pm 10.4$ & $24.3 \pm 4.3$ \\
\hline $\begin{array}{l}\text { Physical non- } \\
\text { aggressive }\end{array}$ & 0.05 & $21 \pm 4.2$ & $17 \pm 7.1$ & $14.2 \pm 6.6$ & $20 \pm 6.3$ \\
\hline $\begin{array}{l}\text { Verbal } \\
\text { aggressive }\end{array}$ & $-0.43^{\star}$ & $5 \pm 2.8$ & $5.8 \pm 3.4$ & $4.7 \pm 3.5$ & $13 \pm 5.3$ \\
\hline \multirow{3}{*}{$\begin{array}{l}\text { Verbal non- } \\
\text { aggressive }\end{array}$} & $-0.43^{\star}$ & $11.5 \pm 6.4$ & $8.6 \pm 7.9$ & $6.9 \pm 2.4$ & $22.7 \pm 9.1$ \\
\hline & \multicolumn{5}{|l|}{ Week 2} \\
\hline & $\begin{array}{l}\text { Pearson } \\
\text { correlation }\end{array}$ & $\begin{array}{l}\text { Moderately better }(4,5) \\
(n=3) \text { (mean } \pm S D)\end{array}$ & $\begin{array}{l}\text { Minimally better }(1,2,3) \\
(n=9)(\text { mean } \pm S D)\end{array}$ & $\begin{array}{l}\text { Stable }(0)(n=8) \\
(\text { mean } \pm S D)\end{array}$ & $\begin{array}{l}\text { Minimally worse }(-1,-2 \text {, } \\
-3)(n=3)(\text { mean } \pm S D)\end{array}$ \\
\hline Total score & 0.06 & $38 \pm 8.5$ & $56.8 \pm 13.9$ & $41.3 \pm 15.4$ & $58.7 \pm 29.6$ \\
\hline $\begin{array}{l}\text { Physical } \\
\text { aggressive }\end{array}$ & 0.08 & $14 \pm 2.7$ & $18.7 \pm 8.0$ & $14 \pm 5.9$ & $18.3 \pm 8.1$ \\
\hline $\begin{array}{l}\text { Physical non- } \\
\text { aggressive }\end{array}$ & 0.21 & $12 \pm 2$ & $20.1 \pm 5.2$ & $12.8 \pm 5.2$ & $17.3 \pm 5.0$ \\
\hline $\begin{array}{l}\text { Verbal } \\
\text { aggressive }\end{array}$ & 0.06 & $6 \pm 3.6$ & $6.1 \pm 2.6$ & $5.5 \pm 4.1$ & $6 \pm 3.6$ \\
\hline $\begin{array}{l}\text { Verbal non- } \\
\text { aggressive }\end{array}$ & -0.22 & $7.3 \pm 4.0$ & $10.8 \pm 5.1$ & $9.3 \pm 7.1$ & $19 \pm 12.1$ \\
\hline
\end{tabular}

CMAI=Cohen-Mansfield Agitation Inventory, GRC=Global Rating of Change, SD=Standard Deviation * $p<0.05$

Figures 


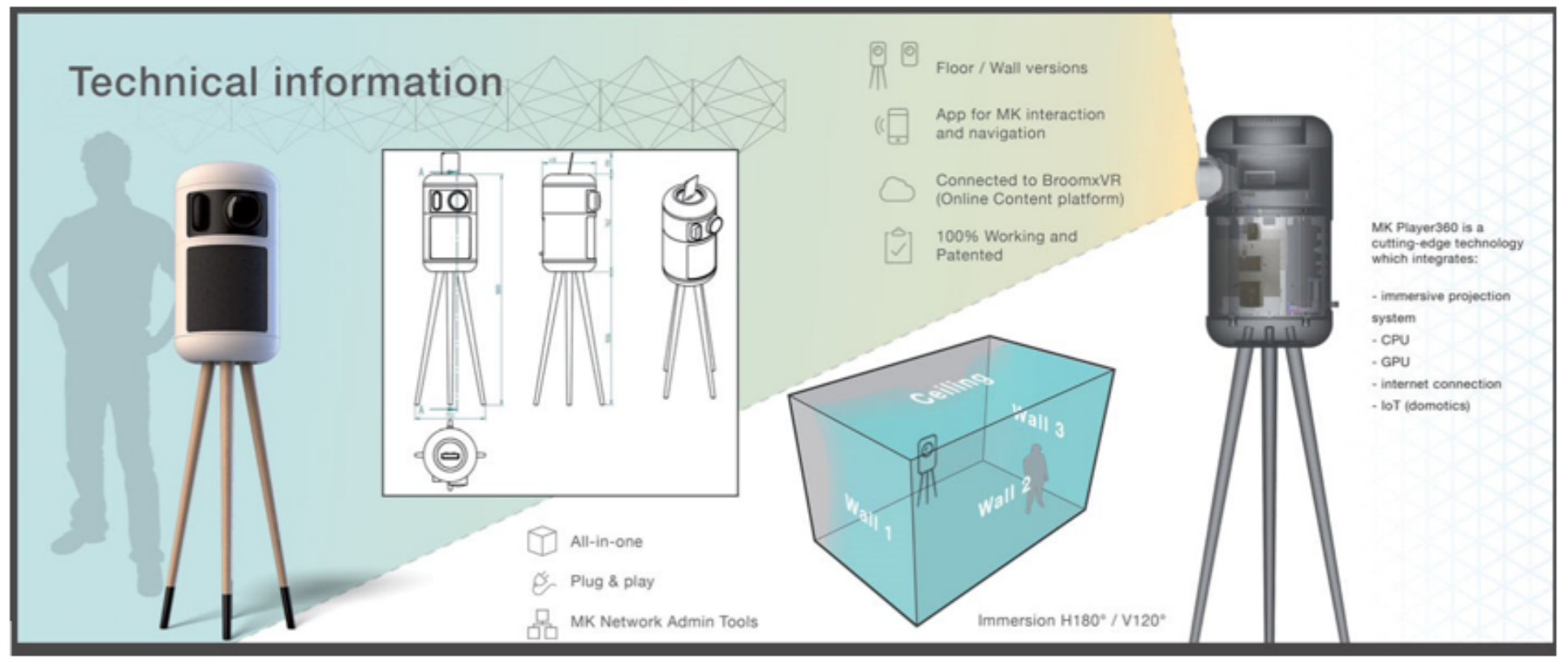

Figure 1

Technical information on Broomx@ ( Reprinted from "MKplayer360" by Broomx Technologies, 2019, Retrieved from http://www.broomx.com/mkplayer360.php Copyright 2019 by Broomx Technologies. Reprinted with permission. 


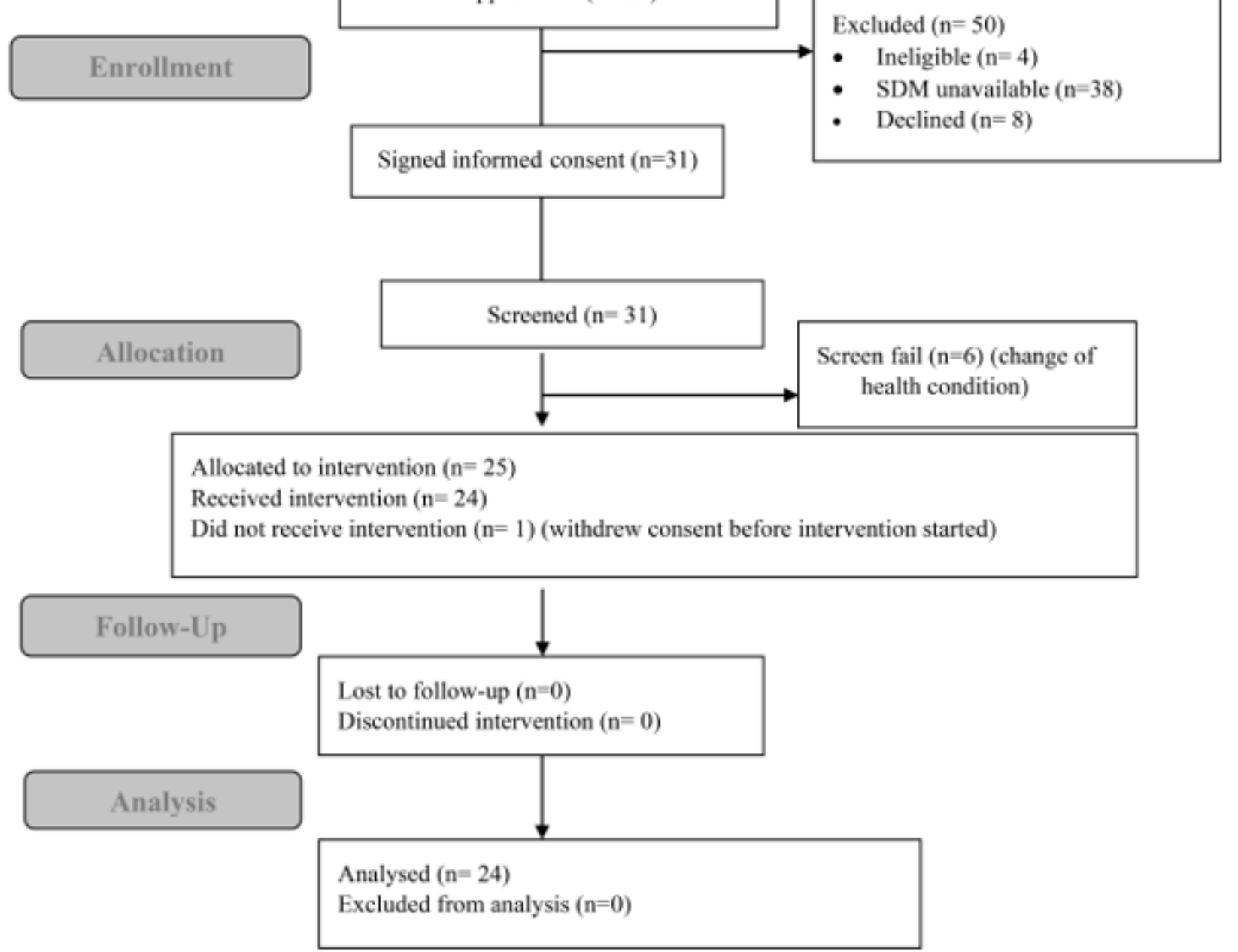

Figure 2

The flow chart for participant enrollment, allocation, follow-up, and analysis. 